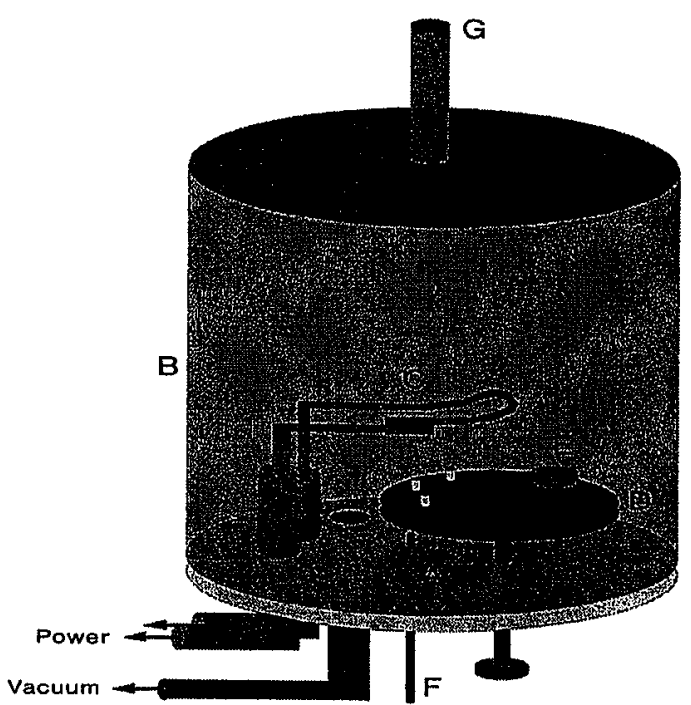

\section{Decarburization of Steel to Ultra-low-carbon Levels by Vacuum Levitation}

Jin LIU and Ralph HARRIS ${ }^{1)}$

INCO Ltd., Copper Cliff, Ontario, Canada.

1) Department of Mining and Metallurgical Engineering, McGill University, 3610 University Street, Montreal, QC H3A 2B2, Canada. E-mail: ralph@minmet.lan.mcgill.ca

(Received on July 10, 1998; accepted in final form on September $22,1998)$

Vacuum levitation experiments were carried out on approximately $1 \mathrm{~g}$ steel samples initially containing from 35 to $2000 \mathrm{ppm}$ (mass) carbon, from 40 to $3300 \mathrm{ppm}$ (mass) sulphur and from 200 to $800 \mathrm{ppm}$ (mass) oxygen at temperatures in the range 1550 to $1850^{\circ} \mathrm{C}$ and at vacuums of 20 and $40 \mathrm{~Pa}^{1}{ }^{1}$ It was found that the rate of decarburization was proportional to the carbon content of the samples. The overall carbon mass transfer coefficient was approximately $1.6 \times 10^{-5} \mathrm{~m} / \mathrm{s}$ and was seen to increase slightly with decreasing chamber pressure. Chemical reaction control was not suggested since the decarburization rate was insensitive to initial sulphur content and the variation associated with levitation temperature due to variation in the initial sample mass.

As shown in Fig. 1, the apparatus consisted of an aluminum base plate, $\mathrm{A}$, over which a plastic bell, B, was placed, the junction being sealed by an O-ring recessed in the base plate. The levitation coil, $\mathrm{C}$, $\left(0.32 \times 10^{-2} \mathrm{~m}(1 / 8 \mathrm{in})\right.$ O.D. with $0.05 \times 10^{-2} \mathrm{~m}(0.02 \mathrm{in})$ wall thickness) with cooling water flowing inside, was connected to the power with O-ring seals and rubber insulation at the junction with the plate. A turntable holding both specimens contained in alumina crucibles and copper crucibles, E, used to hold specimens after experiments, could be rotated by a shaft brought through an O-ring seal in the base plate. A double O-ring sealed rod, $F$, was used to push the specimen up to the levitation coil. In order to prevent the ionisation of gas in the vacuum chamber, the levitation coils were insulated by silicone rubber tape. Five specimens could be held on the turntable, $D$, at the one time inside the vacuum chamber. The volume of the vacuum chamber was about twenty litres. The levitation time was limited to a total of $60 \mathrm{sec}$ because a longer levitation time may have damaged the insulation of the levitation coil due to overheating. A glass tube was placed inside the levitation coil to prevent vaporised iron from condensing on the levitation coils. The tube was replaced every experiment due to the impairment of observation caused by the black condensate formed on the inner wall of the tube. The weight gain of the glass tube was used to estimate the weight loss of the specimen by evaporation during
Fig. 1. Schematic of vacuum levitation apparatus. A-Baseplate; B-Transparent vacuum chamber; C Levitation coil; D-Turntable; E-Copper quench moid; F - Pushrod

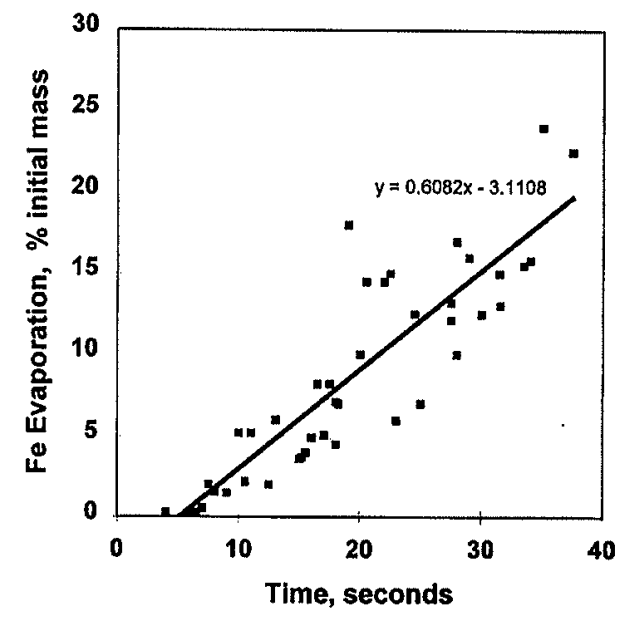

Fig. 2. Loss of iron by evaporation.

the vacuum levitation experiment. The droplet surface temperature was measured by an optical pyrometer that had a machine imprecision of $+/-25 \mathrm{~K}$ and a measurement inaccuracy of $+/-25 K$, estimated. An indirect method to estimate the droplet temperature was also used and is explained below. Specimens were sent to Dofasco Ltd. (Hamilton, Ontario) for LECO analyser carbon and sulphur analysis.

Figure 2 shows that fifteen to $25 \%$ of the initial mass of the specimens, as determined from the weight gain of the glass tube, was evaporated after 25 to $35 \mathrm{sec}$ of vacuum levitation. The rate of iron evaporation was used to estimate the droplet temperature by assuming that the rate of iron evaporation was determined by Langmuir evaporation, ${ }^{2)}$ i.e.:

$$
n_{\mathrm{Fe}}=\left(\frac{R T}{2 \pi M_{\mathrm{Fe}}}\right)^{1 / 2}\left(\frac{P_{\mathrm{Fe}}}{R T}\right) \approx 1.3 \times 10^{-4} \mathrm{~g} \mathrm{~mol} / \mathrm{s}_{\text {measured }}
$$

where $n_{\mathrm{Fe}}$ is the molar flux of iron, $M_{\mathrm{Fe}}$ is the molar 


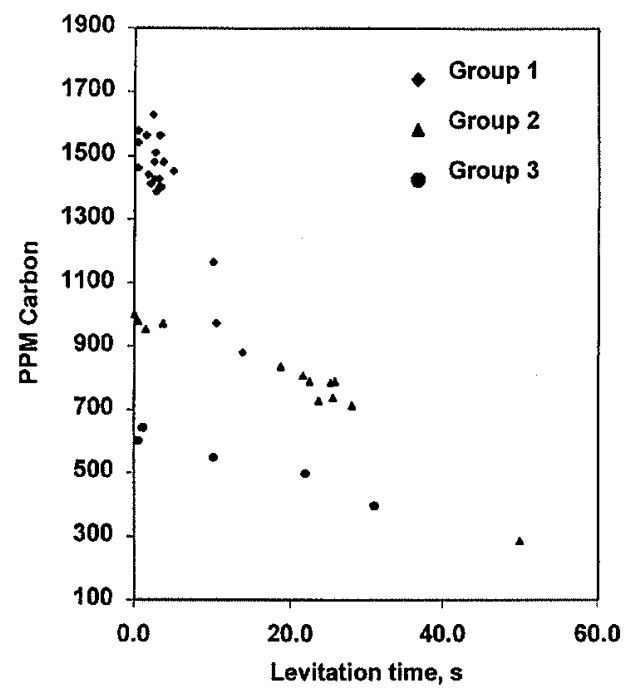

Fig. 3. Summary of decarburization data for Groups 1 to 3 specimens.

Vacuum: $40 \mathrm{~Pa}$

Initial Carbon (ppm) Group 1: 1870, Group 2: 1230 , Group 3: 880

Initial Oxygen (ppm) Group 1: 800, Group 2: 300, Group 3: 200

Initial Sulphur (ppm) Group 1: 220, Group 2: 170, Group 3: 3300

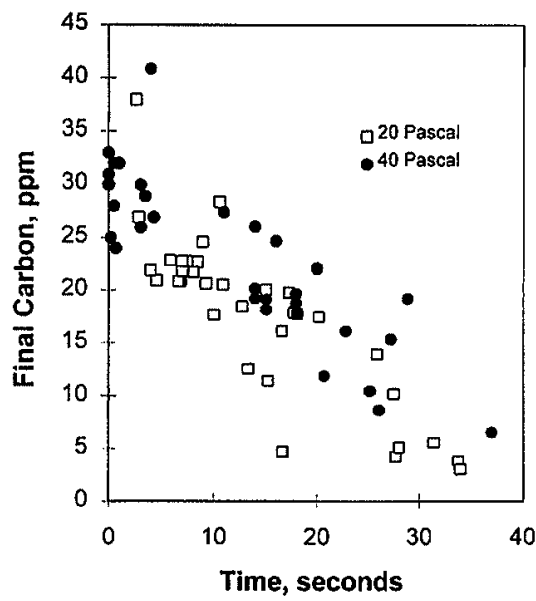

Fig. 4. Summary of Group 4 specimens. Initial Carbon (ppm) - 35 Initial Oxygen (ppm) -350 Initial Sulphur (ppm) -40

mass of iron and $P_{\mathrm{Fe}}$ is the partial pressure of iron. The temperature estimated by this method was approximately $1850^{\circ} \mathrm{C}$ and is the one used in the analysis that follows.

The loss of iron via evaporation resulted in a change in the surface area to volume ratio of the droplet during decarburization. To compensate for this, the measured value of final carbon content was adjusted as follows:

$$
\underline{\mathrm{C}}_{\mathrm{adjusted}}=\underline{\mathrm{C}}_{\text {measured }}\left(1-\frac{a}{100}\right)
$$

and the area to volume ratio for the initial sample was used in the rate calculations here. In Eq. (2), $\underline{C}$ is the dissolved carbon content (ppm) and $a$ is the percentage of weight reduction by evaporation. The decarburization
Table 1. Summary of the decarburization rate data.

\begin{tabular}{lccccc}
\hline & $\begin{array}{c}\text { Pressure } \\
(\mathrm{Pa})\end{array}$ & $\begin{array}{c}d C / d t \\
(\mathrm{ppm} / \mathrm{s})\end{array}$ & $\begin{array}{c}\text { Intercept } \\
(\mathrm{ppm} \mathrm{C})\end{array}$ & $r$ & $\begin{array}{c}\text { Typical C } \\
(\mathrm{ppm})\end{array}$ \\
\hline Group 1 & 40 & -22 & 1532 & 0.365 & 1500 \\
Group 2 & 40 & -12.3 & 1032 & 0.951 & 900 \\
Group 3 & 40 & -7 & 627 & 0.974 & 550 \\
Group 4 & 40 & -0.64 & 31 & 0.86 & 20 \\
Group 4 & 20 & -0.73 & 28 & 0.831 & 20 \\
\hline
\end{tabular}

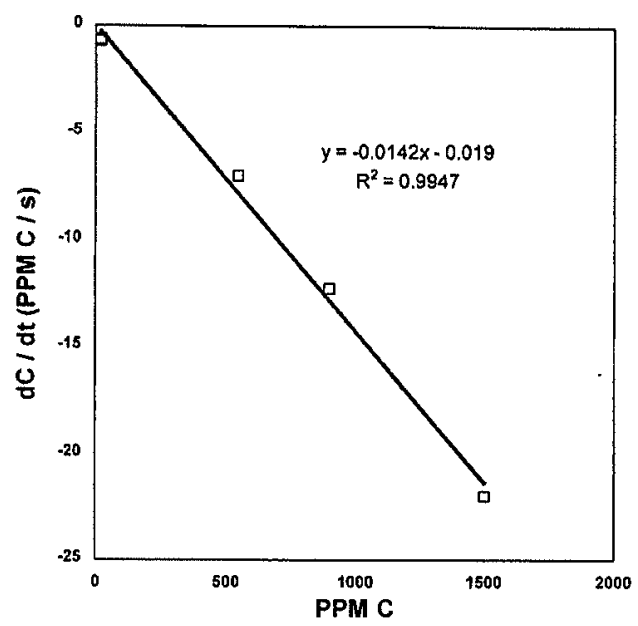

Fig. 5. Decarburization rates as a function of typical carbon contents during decarburization. Best-fit linear regression line has been forced through the origin.

results are summarised in Figs. 3 and 4. It is quickly seen that there is variability in the rate of decarburization of each group of specimens and that the intercept of a best fit line for each set of specimens would be less than the nominal carbon assay for those specimens. Table 1 presents the linear regression data for each of the group of specimens where the slopes of the best fit lines from Figs. 3 and 4 are reported as the decarburization rate, $d C / d t(\mathrm{ppm} \mathrm{C} / \mathrm{s})$. The intercepts for each of the best fit lines are also given as well as the value of the correlation coefficient. A value of the typical carbon content while the sample was being decarburized for each of the groups of specimens is also given. In some instances, the extent of decarburization exceeded that possible for the initial dissolved oxygen. It is believed that there could have been sufficient oxygen supply from the vacuum chamber atmosphere to account for these apparent anomalies. ${ }^{1)}$

Figure 5 plots the calculated decarburization rate for each group of specimens against the typical carbon content for that group and shows that the rate of decarburization is linearly proportional to the carbon content which implies that the decarburization was first order with respect to the carbon in the droplet. Such a relationship can be expressed as:

$$
\ln \left(\underline{\mathrm{C}}_{\mathrm{ppm}}\right)=k_{\mathrm{ov}}\left(\frac{A}{V}\right)_{\mathrm{droplet}} t+\psi
$$

where $k_{\mathrm{ov}}$ is the overall carbon mass transfer coefficient for decarburization, $(A / V)_{\text {drop }}$ is the surface area to volume ratio for the levitated droplet (approximately $900 \mathrm{~m}^{-1}$ for a $1 \mathrm{~g}$ drop of steel), $t$ is the time of de- 
carburization and $\psi$ is a constant of integration. The slope of the plot in Fig. $5,\left(0.0143 \mathrm{~s}^{-1}\right)$ is equal to the overall mass transfer coefficient for decarburization, $k_{\mathrm{ov}}$, times the surface area to volume ratio for the levitated droplet, $(A / V)_{\text {drop }}$, hence the measured value of the overall carbon mass transfer coefficient for decarburization, $k_{\mathrm{ov}}$, was approximately $1.6 \times 10^{-5} \mathrm{~m} / \mathrm{s}$.

The dependence of the decarburization rate on the typical carbon content indicates that either the mass transfer of carbon within the droplet to the droplet surface or mass transfer of carbon monoxide away from the droplet surface in the gas phase, since the molar flux of carbon equals that of carbon monoxide, the predominant product of reaction, limits the decarburization rate. The molar flux of carbon in the liquid and gas side boundary layers $\left(n, \mathrm{~mol} / \mathrm{m}^{2} / \mathrm{s}\right)$ can be represented as follows when the $\mathrm{CO}$ is dilute in the gas phase:

$$
\begin{gathered}
n_{\mathrm{C}}^{\text {liquid }}=0.583 k_{\mathrm{l}}\left(C_{\mathrm{C}}^{\text {bulk liquid }}-C_{\mathrm{C}}^{\text {interface }}\right) \\
n_{\mathrm{C}}^{\text {gas }}=\frac{k_{\mathrm{g}}}{R T}\left(p_{\mathrm{CO}}^{\text {intferace }}-p_{\mathrm{CO}}^{\text {bulk gas }}\right) \ldots .
\end{gathered}
$$

where $k$ is a mass transfer coefficient $(\mathrm{m} / \mathrm{s}), C$ is the concentration of carbon (ppm), $p$ is the partial pressure $(\mathrm{Pa}), R$ is the gas constant $(8.314 \mathrm{~J} / \mathrm{mol} / \mathrm{K})$ and $T$ is the temperature $(\mathrm{K})$. The coefficient, 0.583 , arises from the conversion between $\mathrm{ppm}$ (mass) and $\mathrm{gmol} / \mathrm{m}^{3}$. The relationship between the carbon concentration at the interface and the carbon monoxide partial pressure $(\mathrm{Pa})$ at the interface can be obtained from the Gibbs energy of the chemical reaction ${ }^{3)}$ :

$$
\underline{\mathrm{C}}_{\%}+\underline{\mathrm{O}}_{\%}=\mathrm{CO} \quad \Delta G_{2123 \mathrm{~K}}^{\circ}=-104011 \mathrm{~J} / \mathrm{mol}
$$

i.e.:

$$
p_{\mathrm{CO}}^{2123 \mathrm{~K}}=0.367 \underline{\mathrm{O}}_{\mathrm{pmm}} \underline{\mathrm{C}}_{\mathrm{pm}}
$$

If the oxygen content of the samples is taken to be roughly constant at about $350 \mathrm{ppm}$, which is reasonable for Group 4 specimens, then the partial pressure of carbon monoxide is proportional to the carbon content as follows:

$$
p_{\text {CO }}^{2123 \mathrm{~K}}=129 \mathrm{C}_{\mathrm{ppm}}
$$

At steady state, the liquid side flux of carbon equals the gas side flux of carbon, hence the rate equations above can be combined to yield:

$$
n_{\mathrm{C}}=\left(\frac{1}{0.583 k_{\mathrm{I}}}+\frac{R T}{129 k_{\mathrm{g}}}\right)^{-1}\left(C_{\mathrm{C}}^{\text {bulk liquid }}-\frac{p_{\mathrm{CO}}^{\text {bulk gas }}}{129}\right) \ldots
$$

Sherwood numbers, $N_{\mathrm{Sh}}\left(=k_{\mathrm{g}} d / D\right)$ and gas phase mass transfer coefficients, $k_{g}$, can be estimated for mass transfer from a sphere submerged in a flowing fluid ${ }^{4)}$ and binary gas phase diffusivities, $D$, from the kinetic theory of gases. ${ }^{5)}$ In such an analysis, $d$ is taken as the diameter of the submerged sphere. At the present temperatures $\left(1850^{\circ} \mathrm{C}\right.$, estimated) and pressures $\left(77 \mathrm{~Pa},{ }^{*}\right.$ assuming that the region inside the tube was at the partial pressure of iron at $\left.1850^{\circ} \mathrm{C}\right), N_{\mathrm{sh}}$ is roughly $2, d$ is $0.67 \mathrm{~cm}$ and $D$ has a value of about $0.4 \mathrm{~m}^{2} / \mathrm{s}$, thus $k_{\mathrm{g}}$ was approximately $120 \mathrm{~m} / \mathrm{s}$. The liquid phase mass transfer coefficient for carbon was then calculated as $2.8 \times 10^{-5}$ $\mathrm{m} / \mathrm{s}$ and gas phase transfer should exhibit minimal control at these pressures on the decarburization rate. This was a surprise since it was thought that the internal mixing caused by the strong magnetic levitation field would be expected to produce high mass transfer rates within the droplet.

Reported industrial experience suggested that the rate of decarburization decreased faster than the decrease in carbon content at ultra-low-carbon levels, that is, the order of the decarburization process was greater than unity and the achievement of ultra-low levels of carbon would take increasingly long times. ${ }^{6)}$ This has not been observed in the present work. The production of ultralow-carbon steels can be represented by a first order process with respect to carbon content.

\section{REFERENCES}

1) J. Liu: M. Eng. Thesis, McGill University, (1991)

2) L. Jara: Ph. D. Thesis, McGill University, (1997).

3) C. Bodsworth: The Physical Chemistry of Iron and Steel Manufacture, Longman, London, (1972), 378.

4) R. B. Bird, E. W. Stewart and E. N. Lightfoot: Transport Phenomena, Wiley Int., New York, NY, (1960), 409.

5) R. B. Bird, E. W. Stewart and E. N. Lightfoot: Transport Phenomena, Wiley Int., New York, NY, (1960), 510.

6) T. Kuwabara, K. Umezawa, K. Mori and H. Watanabe: Trans. Iron Steel Inst. Jpn., 28 (1988), 305.

\footnotetext{
* The value used for the chamber pressure is greater than the measured pressure and since it is believed that there may have been a localised higher pressure region inside the glass tube due to the evaporation of iron. In practice, the actual pressure in the vicinity of the droplet was likely somewhere between these two extremes and hence the effect of pressure would not have been quite as great as the mathematical analysis suggests.
} 